\title{
Intra-adrenal factors are not involved in the differential control of cortisol and adrenal androgens in human adrenals
}

\author{
Ursula Fearon, Dara Clarke, T Joseph McKenna and Sean K Cunningham \\ Department of Endocrinology, St Vincent's Hospital, Elm Park, Dublin 4, Ireland \\ (Correspondence should be addressed to T J McKenna, Department of Endocrinology, St Vincent's Hospital, Elm Park, Dublin 4, Ireland)
}

\begin{abstract}
The differential control of adrenal androgens and cortisol may be due to intra-adrenal factors, which may be age- or sex-related, or due to extra-adrenal factors, such as circulating hormones. The purpose of this study was to identify any intrinsic differences that may exist in steroidogenic production occurring within adrenals obtained from males and females, and any maturational differences that may evolve with age. Using human adrenals from 48 transplant donors ( 32 males, 16 females; ages 560 years), the influences of age and sex on basal production of and ACTH-stimulated cortisol, androstenedione and dehydroepiandrosterone (DHEA) were examined in freshly prepared adrenal cell suspensions. Basal and ACTH-stimulated cortisol, androstenedione and DHEA production were similar in adrenals from males and females and did not correlate significantly with age when the whole group was examined. When steroidogenesis in male and female adrenals was examined separately against age, a significant correlation was observed only for basal and ACTH-stimulated androstenedione in adrenals from males in the younger age group, 5-30 years (basal: $r=0.84, P=0.0001$; ACTH-stimulated: $r=0.52, P=0.007)$. Examination of the relationships between the steroids disclosed that the basal and ACTH-stimulated cortisol/androgen ratios did not correlate significantly with age, but the androstenedione/DHEA ratio showed a significant direct relationship with age in males only (basal: $r=0.53, P=0.006$; ACTH-stimulated: $r=0.5, P=0.01$ ).

These data suggest that the influences of sex and age are minor in the modulation of adrenal steroidogenesis and support the concept that extra-adrenal factors dominate in the differential modulation of adrenal androgens and cortisol. The relationship between the androstenedione/ DHEA ratio and increasing age in men is consistent with the recently reported stimulatory effect of testosterone on adrenal steroidogenesis by induction of the conversion of DHEA to androstenedione.
\end{abstract}

European Journal of Endocrinology 138 567-573

\section{Introduction}

Whereas it is well established that cortisol production is under the control of adrenocorticotrophic hormone (ACTH), it has been known for some time that adrenal androgens are regulated in a more complex manner (1). Adrenal androgens are controlled partly, but not exclusively, by ACTH. Several physiological and pathological situations exist in which there is a divergence of adrenal androgen and cortisol secretion (1-3). Cortisol concentrations are increased in stress and anorexia nervosa, whereas androgen concentrations are suppressed (4). In some patients with partial hypopituitarism, cortisol concentrations are normal and androgen concentrations are suppressed (5). Patients with ectopic ACTH syndrome have increased cortisol concentrations, whereas androgen concentrations are increased, normal or decreased (6). Circulating adrenal androgens demonstrate a striking and unexplained relationship with age. Adrenarche is characterized by an increase in blood concentrations of adrenal androgens at the end of the first decade of life. Serum concentrations of adrenal androgens peak at 20-30 years of age and remain at this level throughout the 4 th and 5 th decade. With ageing, the concentration of adrenal androgens and their response to ACTH decline $(7,8)$. This pattern of adrenal androgen concentrations is seen in both sexes (9) and differs from that of adrenal glucocorticoid, as serum cortisol concentrations and cortisol responsiveness to ACTH remain relatively constant throughout life (8). When ACTH is administered to hypophysectomized chimpanzees, it is adequate to maintain cortisol production but, given alone, it is unable to maintain a normal cortisol/androgen ratio (10). Therefore the evidence suggests that some non-ACTH mechanism, either alone or in combination with ACTH, is involved in the control of adrenal androgens (5).

The control of adrenal androgens may be through the agency of 'intra-adrenal' or 'extra-adrenal' factors. The potential endogenous adrenal gland mechanisms regulating adrenal androgen secretion include maturation and zonation of the adrenal gland (11), adrenal 
blood flow that may expose the inner zone to high concentrations of cortisol (12), and changes in the properties of the adrenal enzymes and their co-factors (13-15). Alternatively, factors outside the adrenal gland have been proposed, such as prolactin (16), growth hormone (17), insulin (18), sex steroids (19, 20 ) and fragments of the ACTH precursor molecule, pro-opiomelanocortin, such as $\beta$-endorphin (21) and joining peptide $(21,22)$. The existence of such a cortical androgen stimulating hormone has been disputed (23$25)$. The present study was designed to examine the influence of ageing and sex on the relative production of cortisol, androstenedione and dehydroepiandrosterone (DHEA), basally and in response to ACTH, and thus enable us to examine the influence of possible endogenous maturational changes that may influence differential production of cortisol and androgens.

\section{Materials and methods}

\section{Subjects}

Human adrenals were obtained at the time of kidney resection from 48 brain dead transplant donors, 32 males aged $28.8 \pm 11.3$ years and 16 females aged $37.3 \pm 21.7$ years (mean \pm s.D.). The large majority of the donors had suffered subarachnoid haemorrhage or head injuries. Before kidney resection, some donors had been pretreated with dexamethasone and desmopressin (DDAVP) or with dopamine and antibiotics. None of the donors had chronic underlying disease that might be expected to influence steroidogenesis. They ranged in age from 5 to 60 years. The study protocol was approved by the Ethics Committee of St Vincent's Hospital.

\section{Cell suspension protocol}

The adrenal cell suspension was prepared at $0-4{ }^{\circ} \mathrm{C}$. Excess fat and connective tissue were removed and the adrenals were chopped into $1 \mathrm{~mm}$ cubes. No attempt was made in these studies to separate cells of the zonae glomerulosa, fasciculata and reticularis. This tissue was incubated in Eagle's modified essential medium (EMEM, Flow Labs, Scotland, 10.105-22) containing collagenase (Sigma, Poole, Dorset, UK, C0130) $2 \mathrm{mg} / \mathrm{ml}$, for $20 \mathrm{~min}$ in a shaking water-bath at $37^{\circ} \mathrm{C}$. After centrifugation at $400 \mathrm{~g}$ for $15 \mathrm{~min}$, the supernatant was discarded. The pellet was resuspended in EMEM containing $0.2 \% \mathrm{BSA}$, and cells were physically dispersed by passage up and down teflon tubing attached to a syringe. This process was repeated three times and dispersed cells were filtered, combined and centrifuged at $400 \mathrm{~g}$ for $15 \mathrm{~min}$. The resultant pellet of adrenal cells was washed in EMEM and centrifuged before final resuspension in EMEM containing BSA $0.5 \%$, calcium $6.4 \mathrm{mmol} / \mathrm{l}$, and vitamin $\mathrm{C}$ $1 \mathrm{mmol} / \mathrm{l}$.
The cells were examined microscopically; the cell count in ethidium bromide acridine orange obtained using a haemocytometer demonstrated that $87 \pm 12.5 \%$ (mean \pm s.D.) of the cells were viable. Three different cell types were observed. The zona glomerulosa cells were identified as small spherical cells containing lipid droplets, and the larger spherical cells were identified as arising from the zona reticularis. Cells from the zona fasiculata were recognized by their irregular shape and abundant lipid droplet content; these cells comprised approximately $50 \%$ of the adrenal cell count. Aliquots of cell suspension, $800 \mu \mathrm{l}$, were added to plastic culture tubes (NUNC 0-43141) that contained $100 \mu$ l EMEM (basal) or ACTH(1-39) (Peninsula Laboratories, Liverpool, England). The final volume was made up to $1 \mathrm{ml}$ with EMEM. The tubes containing cells and additions were incubated in a shaking water-bath under 100\% oxygen for $2 \mathrm{~h}$ at $37^{\circ} \mathrm{C}$. Cells were prepared on 48 separate occasions from 48 pairs of human adrenals. On each occasion, cells were incubated in the absence of ACTH (basal conditions) and in the presence of ACTH $10^{-7} \mathrm{~mol} / \mathrm{l}$ (ACTH-stimulated conditions) in three to five replicate tubes. When steroid production was assessed in these replicate tubes, the variability was usually less than $15 \%$. If large discrepancies occurred, the results of the assay were rejected. Preincubation tubes that contained cells without any added peptide were removed before incubation and stored at $4{ }^{\circ} \mathrm{C}$. At the end of incubation, the cell suspensions were frozen and the intracellular steroids were released into the medium by repeated freezing and thawing. The steroids were measured by specific radioimmunoassay. The protocol was similar to that previously used for guinea-pig adrenal cells (26). The cells were capable of responding to ACTH with a significant increase in production of cortisol, androstenedione and DHEA. In order to standardize steroid production from one cell preparation to another, the values obtained were adjusted for the number of cells present by expressing steroid production as $\mathrm{pmol} / 10^{4}$ cells.

\section{Steroid measurement}

Cortisol was measured by direct radioimmunoassay using antiserum supplied by Guildhay (Guilford, Surrey, England), cortisol-3-(O-carboxymethyl)-oximo [2- $\left.{ }^{125} \mathrm{I}\right]$ iodohistamine (Amersham Int., Amersham, England) and phosphate buffer $0.5 \mathrm{~mol} / \mathrm{l}, \mathrm{pH} 7.4$. Aliquots of cell lysates and standards were incubated in the presence of antibody and radiolabelled cortisol overnight at $4{ }^{\circ} \mathrm{C}$. Unbound cortisol was separated from antibody-bound cortisol using 1\% dextran-gelatin-coated charcoal, followed by centrifugation at 3100 r.p.m. for $15 \mathrm{~min}$. The supernatant was decanted and the radioactivity in the free fraction (the charcoal pellet), was measured using a gamma counter.

Androstenedione and DHEA concentrations were 
measured by radioimmunoassay after extraction of steroids with diethyl ether and further purification by chromatography over celite (27). The androstenedione assay used androstenedione-10-[ $\left.{ }^{125} \mathrm{I}\right]$-iodine derivative (Diagnostic Products UK Ltd, Abingdon, Oxfordshire, England) as the radiolabel and the antiserum was obtained from Radioassay Systems Labs (RSL, Carson, USA; Lot No. 1440 R1/P). The DHEA assay used dehydro-[1, 2, 6, 7- $\left.{ }^{3} \mathrm{H}\right]$-epiandrosterone, (Amersham; code TRK 157) as radiolabel; the antiserum was obtained from ICN Biomedicals Inc. (Diagnostics Division, Costa Mesa, CA 92629, USA, Lot R1-46-21). The specificities, sensitivities and precision of the assays have been reported previously by us (26).

To identify changes in the production of the steroids relative one to another, we utilized androstenedione/ cortisol, DHEA/cortisol and androstenedione/DHEA ratios in both basal and ACTH-stimulated cell suspensions.

\section{Statistical analysis}

Results are reported as mean \pm s.e. Steroid production in the male and female groups was compared using the Mann-Whitney U non-parametric test. The correlation of each group with age was assessed by using regression analysis. A $P$ value $<0.05$ was considered to be statistically significant.

\section{Results}

\section{Cortisol and androgen production in human adrenals in vitro}

Cortisol, androstenedione and DHEA production was similar in cells from adrenal glands obtained from males and females under basal or ACTH-stimulated conditions (Fig. 1). However, when the basal and ACTHstimulated androstenedione/cortisol, DHEA/cortisol and androstenedione/DHEA ratios were compared between males and females, the ACTH-stimulated androstenedione/cortisol ratio (male $0.31 \pm 0.13$, female $0.07 \pm$ 0.06; $P<0.05)$ and androstenedione/DHEA ratio (male $2.7 \pm 0.05$, female $1.5 \pm 0.88 ; P<0.05$ ) were significantly greater in the males. When basal and ACTH-stimulated cortisol, androstenedione and DHEA production was examined against age in the total group, no significant correlation was observed (Table 1 ). However, analysis of values obtained with male and female adrenals separately revealed that, in the male glands, basal and ACTH-stimulated androstenedione concentrations correlated significantly with age ( $r=0.41, \quad P=0.02 ; \quad r=0.47, \quad P=0.007 ; \quad$ Fig. 2 ), although cortisol or DHEA did not correlate significantly with age in the group (Table 1). Basal and ACTHstimulated cortisol, androstenedione and DHEA did not significantly correlate with age in the female group (Table 1). When the male group was divided into almost
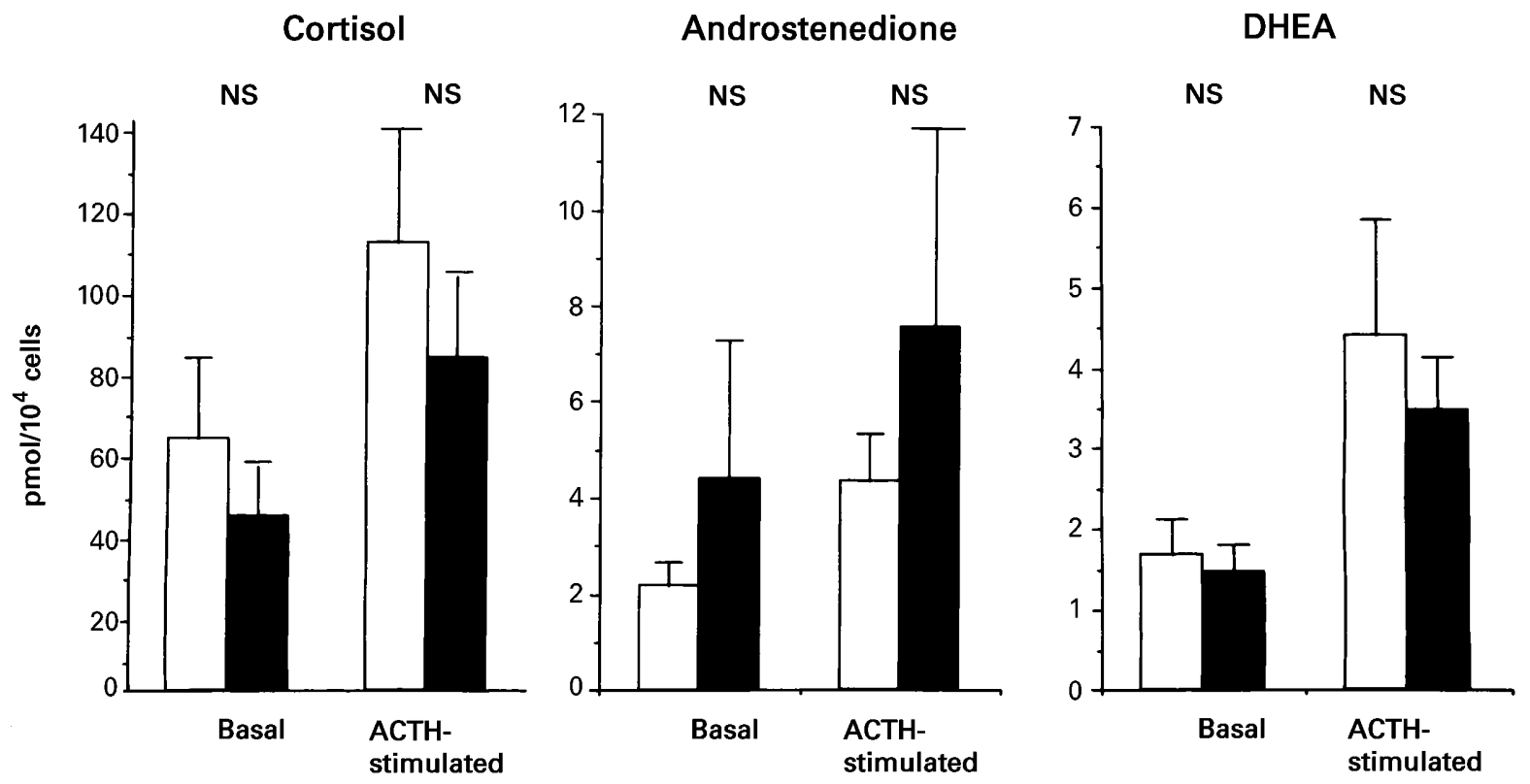

Figure 1 Comparison of basal and ACTH-stimulated cortisol, androstenedione and DHEA production in female (open bars) and male (solid bars) human adrenal cells in vitro. Results are expressed as the mean \pm S.E. of values obtained in 32 male and 16 female human adrenal cell suspensions. Adrenal cells responded to ACTH by producing a significant increase in cortisol, androstenedione and DHEA synthesis. However, there were no significant differences (NS) in production of these steroids between male and female cells under basal or ACTH-stimulated conditions. 
Table 1 Correlation coefficients for basal and ACTH-stimulated cortisol, androstenedione and DHEA production with age (years) in human adrenal cells.

\begin{tabular}{|c|c|c|c|c|c|c|}
\hline \multirow[b]{3}{*}{ Group } & \multicolumn{6}{|c|}{ Correlation coefficient $(r)$} \\
\hline & \multicolumn{2}{|c|}{ Cortisol } & \multicolumn{2}{|c|}{ Androstenedione } & \multicolumn{2}{|r|}{ DHEA } \\
\hline & Basal & ACTH-stimulated & Basal & ACTH-stimulated & Basal & ACTH-stimulated \\
\hline All & 0.23 & 0.21 & 0.22 & 0.31 & 0.14 & 0.12 \\
\hline Male & 0.36 & 0.189 & $0.41^{*}$ & $0.47^{* *}$ & 0.011 & 0.074 \\
\hline Female & 0.114 & 0.346 & 0.135 & 0.114 & 0.48 & 0.382 \\
\hline
\end{tabular}

Significant correlations: * $P=0.02,{ }^{* *} P=0.007$.

equal numbers of specimens from younger (less than 30 years, $n=17$ ) and older (30 years and over, $n=15$ ) individuals, it was observed that the significant correlation of androstenedione with age was confined to the younger subgroup (basal: $r=0.84, P=0.0001$; ACTHstimulated: $r=0.50, P=0.0089$; Fig. 3). No significant correlation was observed when androstenedione was examined against age in adrenals from subjects aged 3060 years (basal: $r=0.29, P=0.36$, ACTH-stimulated: $r=0.21, P=0.417)$.

The possible effects of pretreatment of the donors on the subsequent in vitro steroidogenesis of adrenal cells was examined by subdividing the donors for whom adequate information was available into three groups: those treated with dexamethasone and DDAVP $(n=14)$, those treated with dopamine and antibiotics $(n=15)$ and those who received no pretreatment $(n=7)$. There were no significant differences in basal or ACTH-stimulated cortisol, androstenedione or DHEA production by adrenal cells between the three groups of donors. Furthermore, there were no significant correlations of steroid production with age in any of the three groups.

\section{Cortisol, androstenedione and DHEA interrelationships}

In the male group, basal and ACTH-stimulated androstenedione/DHEA ratios correlated significantly with age $(r=0.53, P=0.006 ; r=0.50, P=0.001$ respectively; Fig. 4), but the DHEA/cortisol or androstenedione/ cortisol ratios did not (Table 2). In the female adrenals, the basal and ACTH-stimulated androstenedione/DHEA, DHEA/cortisol and androstenedione/cortisol ratios all failed to correlate significantly with age (Table 2 ). When the androstenedione/DHEA ratio in males was examined for the two age categories (5-30 years and 30 years and over), the basal androstenedione/DHEA ratio in the younger group correlated significantly with age $(r=0.6$, $P=0.0175)$, but the ACTH-stimulated androstenedione/
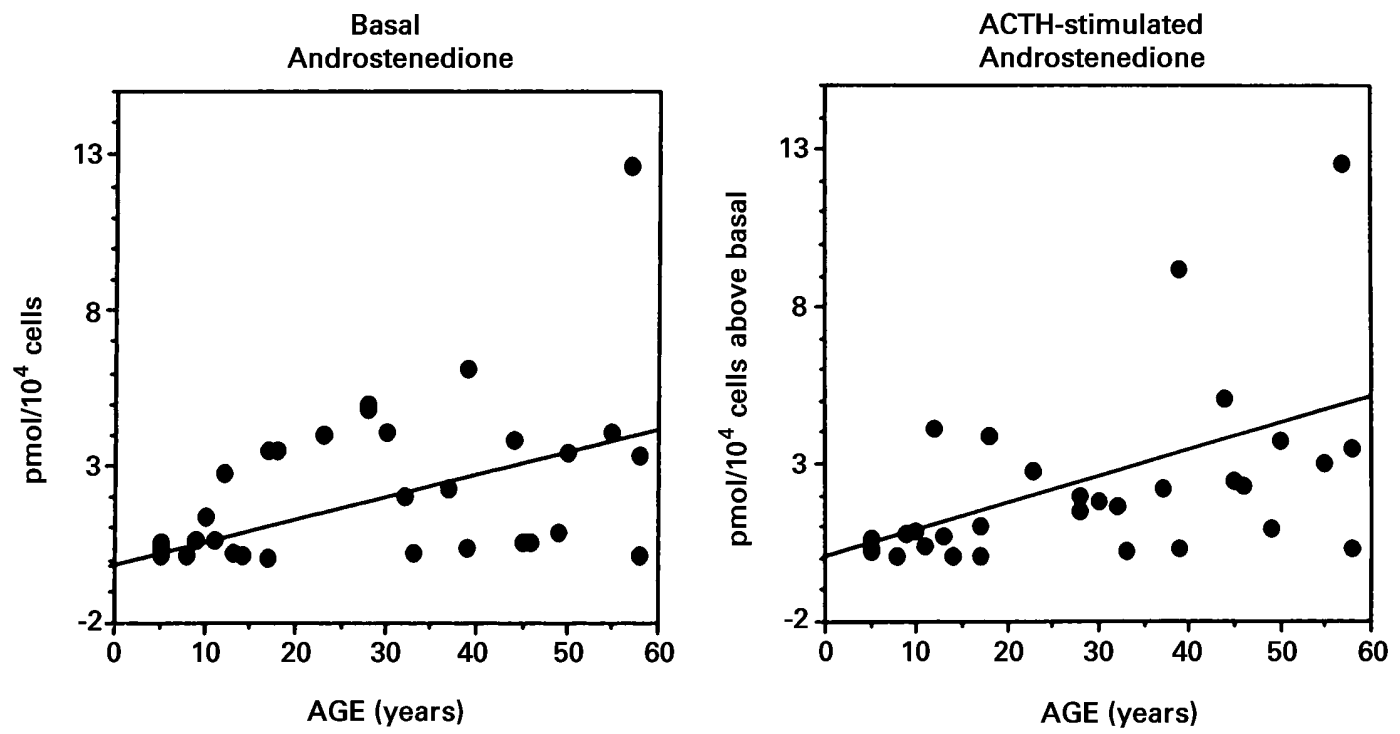

Figure 2 Basal and ACTH-stimulated androstenedione production plotted against age in male human adrenal cells in vitro $(n=32)$. There was a statistically significant correlation of both basal (correlation coefficient $r=0.41, P=0.02$ ) and ACTH-stimulated androstenedione production $(r=0.47, P=0.007)$ with age in male adrenal cells which was not seen in female adrenal cells. 
BASAL Androstenedione

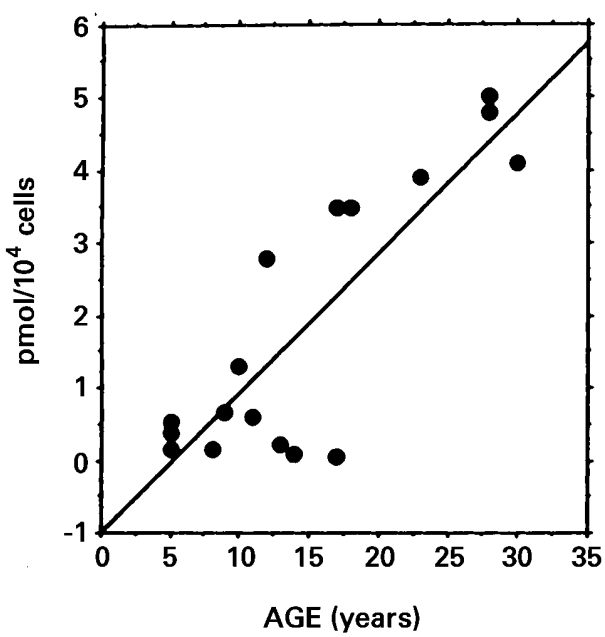

ACTH-stimulated Androstenedione

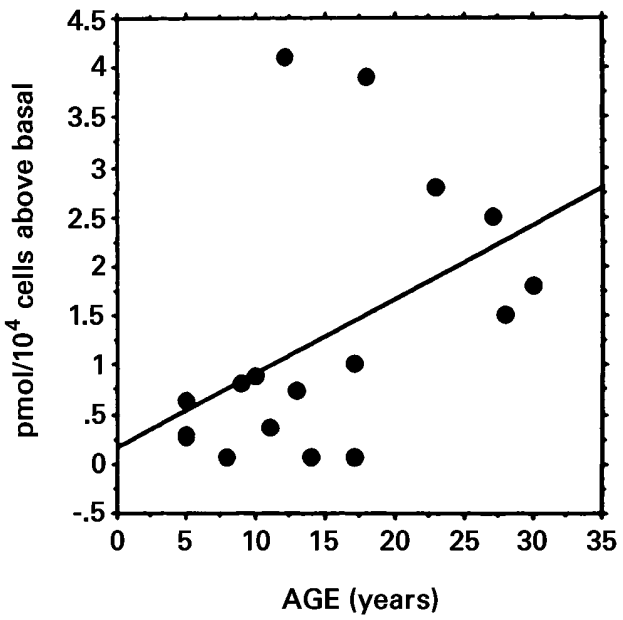

Figure 3 Basal and ACTH-stimulated androstenedione production plotted against age ranging from 5-30 years, in male human adrenal cells in vitro $(n=17)$. There was a statistically significant correlation of both basal (correlation coefficient $r=0.84, P=0.0001$ ) and ACTH-stimulated androstenedione production $(r=0.50, P=0.0089)$ with age in adrenal cells from younger males.

DHEA in the younger group and basal and ACTHstimulated androstenedione/DHEA in the older group did not correlate with age.

\section{Discussion}

Some authors have suggested that the increase in adrenal androgen production at adrenarche is due to some maturational change within the adrenal gland itself (11-13). It has been reported that the zona reticularis, the innermost zone of the adrenal cortex that predominantly secretes adrenal androgens, appears at the time of adrenarche (11). However, no reciprocal decrease in the size of the zona reticularis occurs during the 5 th decade of life, when the adrenal androgen concentrations begin to decline. Another
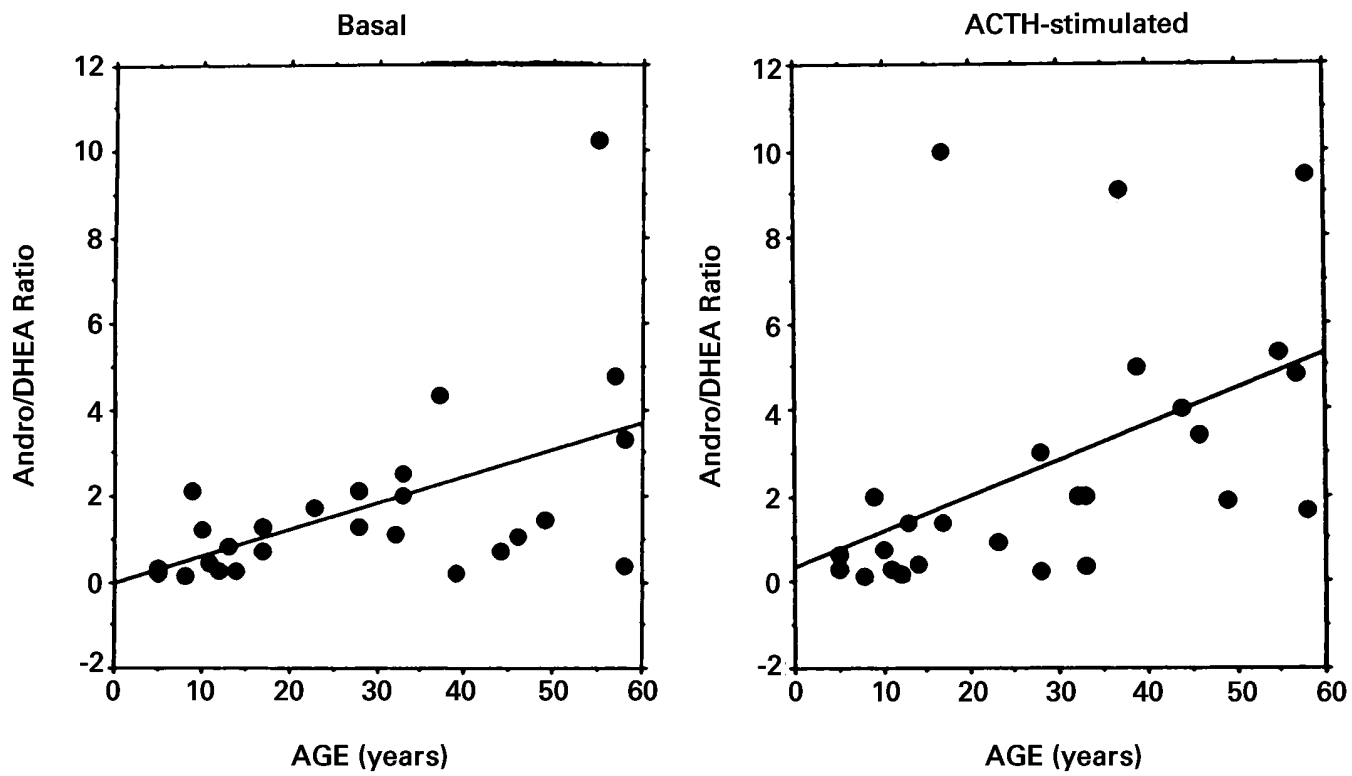

Figure 4 Basal and ACTH-stimulated androstenedione (Andro)/DHEA ratio plotted against age in male human adrenal cells in vitro $(n=32)$. There was a statistically significant correlation of both basal (correlation coefficient $r=0.53, P=0.006)$ and ACTH-stimulated androstenedione/DHEA ratio $(r=0.50, \mathrm{P}=0.001)$ with age in male adrenal cells which was not seen in female adrenal cells. 
Table 2 Correlation coefficients for the relationship of basal and ACTH-stimulated androstenedione (Andro)/DHEA, DHEA/cortisol and androstenedione/cortisol ratios with age (years) in male and female human adrenal cells.

\begin{tabular}{|c|c|c|c|c|c|c|}
\hline \multirow[b]{3}{*}{ Group } & \multicolumn{6}{|c|}{ Correlation coefficient $(r)$} \\
\hline & \multicolumn{2}{|c|}{ Andro/DHEA } & \multicolumn{2}{|c|}{ Andro/cortisol } & \multicolumn{2}{|c|}{ DHEA/cortisol } \\
\hline & Basal & ACTH-stimulated & Basal & ACTH-stimulated & Basal & ACTH-stimulated \\
\hline Male & $0.53^{*}$ & $0.50^{* *}$ & 0.383 & 0.355 & 0.23 & 0.199 \\
\hline Female & 0.297 & 0.269 & 0.253 & 0.022 & 0.46 & 0.04 \\
\hline
\end{tabular}

Significant correlations: ${ }^{* *} P=0.001,{ }^{*} P=0.006$.

possible mechanism is that of long-term exposure of the zona reticularis to cortisol as a consequence of blood flow through the adrenal from the outer cortex to the inner, which may bring about an alteration in the enzymes involved in adrenal androgen production (23). It has also been suggested that maturational changes in the activities of some adrenal enzymes (17-hydroxylase, 17-20-lyase and the 3 $\beta$-hydroxysteroid dehydrogenase, $\Delta^{4-5}$ isomerase system) may account for alterations in steroidogenesis favouring androgens (13-15). Alternatively, factors extrinsic to the adrenal may specifically control adrenal androgen biosynthesis and secretion for example, the putative cortical androgen stimulating hormone. Several studies support this concept. Using our human adrenal cell preparations, we have reported that joining peptide and $\beta$-endorphin, peptides arising from the ACTH precursor pro-opiomelanocortin, have androgen-stimulating properties (21). Parker et al. (22) also reported stimulatory effects of joining peptide on adrenal androgen production, but others have not confirmed this $(24,25)$. Evidence also exists that gonadal steroids influence adrenal glucocorticoid and androgen secretion: for example, testosterone increases the adrenal response to ACTH stimulation $(19,20)$. A 60000 molecular weight glycoprotein isolated from human pituitary has been reported to stimulate DHEA but not cortisol secretion (28), and another study has shown that a peptide other than ACTH from human fetal pituitary stimulated DHEAS but not cortisol, in fetal adrenal cells (29).

The present study was undertaken to identify intrinsic differences that may exist in steroidogenesis occurring within adrenal glands from males and females and differences that may evolve with age. We used short-term incubations of freshly prepared human adrenal cells, as these are more likely to reflect in vivo conditions than are cell cultures. Our findings suggest that sex differences and maturational changes of the adrenal gland have only a minor influence in the modulation of adrenal androgens. The only significant relationship with age was observed in young men, and this was confined to androstenedione. We found no significant correlations between age and cortisol or DHEA in male or female adrenal cells, or between age and androstenedione in females or older males. Thus changes in female adrenal androgen production at adrenarche are unlikely to be due to intra-adrenal factors. The absence of any relationship of steroid concentrations with age in women and older men suggests that specific circumstances operate in young men to influence adrenal steroidogenesis. This is consistent with observations that testosterone affects adrenal steroidogenesis by increasing the response of the adrenal androgens to ACTH stimulation (20). Thus the significant correlation observed between androstenedione and age in our young male group may be due to exposure of the adrenal gland in vivo to increasing testosterone concentrations, which occurs in the younger group. However, the mechanism by which testosterone may affect adrenal steroidogenesis has not been defined previously. Oestrogens have been shown to inhibit DHEA production (30), and evidence from clinical studies suggests that androgens may inhibit $11 \beta$-hydroxylase and 21-hydroxylase enzyme activity $(19,31)$. Our data that suggest a direct correlation of age with increasing androstenedione/ DHEA ratios are consistent with increasing conversion of DHEA to androstenedione with age in adrenals from males younger than 30 years, as a result of increased $3 \beta$-hydroxysteroid-dehydrogenase, $\Delta^{4-5}$ isomerase enzyme system activity. The normal increase in blood concentrations of testosterone from testicular origin in young men appears to enhance adrenal conversion of DHEA to androstenedione.

While it is theoretically possible that the pretreatment of the donors might effect subsequent steroidogenesis in the adrenal cells, we observed no differences between cortisol or androgen production in adrenal cells from donors who had no pretreatment and those pretreated with dexamethasone and DDAVP or dopamine and antibiotics. The lack of any effect of donor pretreatment on subsequent steroidogenesis suggests that any such influence on the adrenal is mediated via an acute extra-adrenal mechanism. Furthermore, the specific steroidogenic pattern seen in the adrenals from young men only was not obscured either by stress or by pretreatment of donors. Thus the model used provides useful new insights into the differential control of adrenal glucocorticoid and androgen production.

Adrenal androgen production did not correlate with age or sex, with the exception of androstenedione in 
younger male adrenals, suggesting that factors exogenous to the adrenal gland are more important in the control of adrenal androgens than are intrinsic changes. Indeed, it is possible that the correlation of androstenedione production with age in young male adrenals was due to an increasing in vivo effect of testicular testosterone on adrenal $3 \beta$-hydroxysteroid dehydrogenase, $\Delta^{4-5}$ isomerase enzyme system activity. Thus our data support the concept that it is "extraadrenal' rather than 'intra-adrenal' factors that dominate in the differential modulation of androgens and cortisol production. However, the identity of this 'extraadrenal' factor has yet to be elucidated.

\section{Acknowledgements}

The authors wish to thank the Transplant Co-Ordination Team in Beaumont Hospital, Dublin, Ireland, for their assistance in obtaining human adrenal tissue.

This work was performed with the aid of a grant from the Health Research Board of Ireland.

\section{References}

1 McKenna TJ \& Cunningham SK. The control of adrenal androgen secretion. Journal of Endocrinology 1991129 1-3.

2 Bondy PK. Disorders of the adrenal cortex. In Textbook of Endocrinology, pp 816-890. Eds JD Wilson \& DW Foster Philadelphia: WB Saunders, 1985.

3 Parker LN. Control of adrenal androgens. In Adrenal Androgens In Clinical Medicine, pp 30-57. New York: Academic Press, 1989.

4 Winter J, Goirtsman HG, George DT, Kaye WH, Loriaux DL \& Cutler Jr GB. Adrenocorticotropin stimulated adrenal androgen secretion in anorexia nervosa. Journal of Clinical Endocrinology and Metabolism 198561 693-697.

5 Cutler GB Jr, Davis SE, Johnsonbaugh R \& Loriaux DL. Dissociation of cortisol and androgen secretion in patients with secondary adrenal insufficiency. Journal of Clinical Endocrinology and Metabolism $197949604-609$.

6 Cunningham SK \& McKenna TJ. Dissociation of adrenal androgen and cortisol secretion in Cushing's syndrome. Clinical Endocrinology 199441 795-800.

7 Cutler GB Jr, Gleen M, Bush M, Hodgen GD, Graham GE \& Loriaux DL. Adrenarche: a survey of rodents, domestic animals and primates. Endocrinology 1978103 2112-2118.

8 Parker LN. Aging and menopause. In Adrenal Androgens In Clinical Medicine pp 118-134. New York: Academic Press, 1989.

9 Migeon CJ. Keller AR, Laurence B \& Shepard TH. Dehydroepiandrosterone and androsterone levels in human plasma: effect of age and sex; day to day and diurnal variation. Journal of Clinical Endocrinology and Metabolism 195717 1051-1062.

10 Albertson B, Hobson W, Burnett B, Turner PT, Clark RV, Schiebinger RJ et al. Dissociation of cortisol and androgen secretion in the hypophysectomised, ACTH-replaced chimpanzee. Journal of Clinical Endocrinology and Metabolism 198459 13-19.

11 Dhom G. The prepubertal and pubertal growth of the adrenal. Beitrage zur Pathologie 1973150 357-377.

12 Kahri AI, Voutrilainen R \& Salmenpera M. Differential biological action of corticosteroids, corticosterone and cortisol, as a basis of zonal function of adrenal cortex. Acta Endocrinologica 197991 329-337.

13 Schiebinger RJ, Albertson BD, Cassorla FG, Bowyer DW, Geelhoed G.W , Cutler GB Jr et al. The developmental changes in plasma adrenal androgens during infancy and adrenarche are associated with changing activities of adrenal microsomal 17-hydroxylase and 17, 20 desmolase. Journal of Clinical Investigation 198167 1177-1182.

14 Byrne GC, Perry YS \& Winter JS. Kinetic analysis of adrenal 3-beta hydroxysteroid dehydrogenase activity during human development. Journal of Clinical Endocrinology and Metabolism 198560 934-939.

15 Yoshiyuk S, Toshihiko Y, Ryochi T, Ryusuke N, Yoshihiro N, Masfumi $\mathrm{H}$ et al. High expression of cytochrome b5 in adrenocortical adenomas from patients with Cushing's syndrome associated with high secretion of adrenal androgens. Journal of Clinical Endocrinology and Metabolism 199376 1286-1290.

16 Albertson BD, Sienkiewicz ML, Kimball D, Munabi A, Cassorla FC \& Loriaux DL. New evidence for a direct effect of prolactin on adrenal steroidogenesis enzyme activity in rats. Endocrine Research $198713317-333$.

17 Brown DJ, Ginz B \& Oakey RE. Effect of polypeptide hormone preparations on steroid production by the human fetal adrenal gland during superfusion. Journal of Endocrinology 197870 60-61.

18 Nestler JE \& Kahwash Z. Sex-specific action of insulin to acutely increase the metabolic clearance rate of dehydroepiandrosterone in humans. Journal of Clinical Investigation 199494 1484-1489.

19 Vermesh M, Silva PD, Rosen GF, Vijod AG \& Lobo RA. Effect of androgen on adrenal steroidogenesis in normal women. Journal of Clinical Endocrinology and Metabolism 198866 128-130.

20 Polderman KH, Gooren LJG \& Van der Veen EA. Testosterone administration increases adrenal response to adrenocorticotrophin. Clinical Endocrinology 199440 595-601.

21 Clarke D, Fearon U, Cunningham SK \& McKenna TJ. The steroidogenic effects of $\beta$-endorphin and joining peptide: a potential role in the modulation of adrenal androgen production. Journal of Endocrinology 1996151 301-307.

22 Parker LN, Lifrak E, Gelfand R, Lee J, Shively T, Kaplan V et al. Isolation, purification, synthesis and binding of human adrenal gland cortical androgen stimulating hormone. Endocrine Journal $19931441-445$.

23 Anderson DC. The adrenal androgen stimulating hormone does not exist. Lancet 1980 ii 454-456.

24 Penhoat A, Sanchez, P, Jaillard C, Langlois D, Begeot M \& Saez JM. Human pro-opiomelanocortin(79-96) a proposed cortical androgen-stimulating hormone, does not affect steroidogenesis in cultured human adult adrenal cells. Journal of Clinical Endocrinology and Metabolism 199172 23-26.

25 Mellon SH, Shively JE \& Miller, WL. Human pro-opiomelanocortin(79-96) a proposed androgen stimulating hormone, does not affect steroidogenesis in cultured human foetal adrenal cells. Journal of Clinical Endocrinology and Metabolism 199172 19-21.

26 O'Connell Y, McKenna TJ \& Cunningham SK. Effects of proopiomelanocortin derived peptides on adrenal steroidogenesis in guinea-pig adrenal cells in vitro. Journal of Steroid Biochemistry and Molecular Biology 199344 77-83.

27 Abraham GE \& Chakmakjian ZH. Serum steroid levels during the menstrual cycle in bilaterally adrenalectomised women. Journal of Clinical Endocrinology and Metabolism 197337 581-587.

28 Parker LN, Lifrak ET \& Odell WD. A 60000 molecular weight human pituitary glycoprotein stimulates adrenal androgen secretion. Endocrinology 1983113 2092-2096.

29 Brubaker PL, Baird A, Bennett H, Browne C \& Solomon S. Corticotrophic peptides in the human fetal pituitary. Endocrinology $19821111150-1155$.

30 Albrecht ED \& Pepe GJ. Effects of estrogen on DHEA formation by baboon fetal adrenal cells in vitro. American Journal of Obstetrics and Gynecology 1987156 1275-1280.

31 Fujieda K, Faiman C, Feyes FI \& Winter JSD. The control of steroidogeneis by human fetal adrenal cells in tissue culture. IV The effects of exposure to placental steroids. Journal of Clinical Endocrinology and Metabolism 1982 54 89-94.

Received 29 June 1997

Accepted 22 January 1998 